$11-1-2015$

\title{
Approaches for Detection of Unstable Processes: A Comparative Study
}

\author{
Yerriswamy Wooluru \\ J S S Academy of Technical Education, Bangalore, India, ysprabhu@gmail.com \\ D. R. Swamy \\ JS S Academy of Technical Education, Bangalore, India \\ P. Nagesh \\ JSS Centre for Management Studies, Mysore, Indi
}

Follow this and additional works at: http://digitalcommons.wayne.edu/jmasm

Part of the Applied Statistics Commons, Social and Behavioral Sciences Commons, and the Statistical Theory Commons

\section{Recommended Citation}

Wooluru, Yerriswamy; Swamy, D. R.; and Nagesh, P. (2015) "Approaches for Detection of Unstable Processes: A Comparative Study," Journal of Modern Applied Statistical Methods: Vol. 14 : Iss. 2 , Article 17.

DOI: $10.22237 /$ jmasm/1446351360

Available at: http://digitalcommons.wayne.edu/jmasm/vol14/iss2/17

This Regular Article is brought to you for free and open access by the Open Access Journals at DigitalCommons@WayneState. It has been accepted for inclusion in Journal of Modern Applied Statistical Methods by an authorized editor of DigitalCommons@WayneState. 


\section{Approaches for Detection of Unstable Processes: A Comparative Study}

\section{Cover Page Footnote}

This work is supported by JSSMVP Mysore. I, sincerely thank to my Guide Dr.Swamy D.R, Professor and Head of the Department, Industrial Engineering \&Management, JSSATE Bangalore and Co-Guide Dr P.Nagesh, Professor, Department of Management studies, SJCE, Mysore. 


\section{Approaches for Detection of Unstable Processes: A Comparative Study}

\author{
Yerriswamy Wooluru \\ JSS Academy of Tech. Ed. \\ Bangalore, India
}

\author{
Dr. D. R. Swamy \\ JSS Academy of Tech. Ed. \\ Bangalore, India
}

\author{
Dr. P. Nagesh \\ JSS Centre for Mgmt. Stud. \\ Mysore, India
}

A process is stable only when parameters of the distribution of a process or product characteristic remain same over time. Only a stable process has the ability to perform in a predictable manner over time. Statistical analysis of process data usually assume that data are obtained from stable process. In the absence of control charts, the hypothesis of process stability is usually assessed by visual examination of the pattern in the run chart. In this paper appropriate statistical approaches have been adopted to detect instability in the process and compared their performance with the run chart of considerably shorter length for assessing its patterns and ensuring the process stability.

Keywords: $\quad$ Process stability, run chart patterns, run test, unstable process

\section{Introduction}

The run chart is a most effective and widely used tool for monitoring the stability of a process by displaying the data to make process performance visible. As long as the series of points in time exhibit a random pattern, the process is assumed to have constant mean and standard deviation and no autocorrelation (i.e. stable). While run charts focus more on time pattern, a control chart focuses on acceptable limits of the process data. However, in many industrial situations, it becomes necessary to estimate process parameter whose stability cannot be monitored using control charts due to lack of data and time for establishing control limits. In the absence of properly established control charts, process stability can be evaluated with the help of run chart trend and its pattern, which can be detected by applying run rules and to conclude the assignable causes present in the process.

In run chart, each observation of a sample have a time variable representing the time of each data point is measured when data have time related behavior, run charts are familiar tools to visualize the process behavior. Also Deming (1986) pointed that when processes ought to behave randomly overtime, run charts can

\footnotetext{
Yerriswamy Wooluru is an Associate Professor. Email him at: jssateb.ac.in.
} 


\section{APPROACHES FOR DETECTION OF UNST ABLE PROCESSES}

help to identify nonrandom behavior, which can unearth potential for improvement. Run charts can be used as one of the important tools for diagnosing and solving various industrial problems, nonrandom patterns are indicative of process instability. Depending on the causes of process instability the non-random patterns can be of different types. The SQC Handbook of Western Electric illustrated various types of unnatural or nonrandom patterns that may occur in the run chart (Western Electric, 1956). Among these, six types of non-random patterns of individual observations are upward shift, downward shift, increasing trend, decreasing trend, cyclic and systematic patterns.

Various statistical tools, such as Regression analysis, ANOVA method, SR test, INSR test, and Levene's test have been used to assess the process location and variation to detect statistical stability of the forging process. These tools have also been compared with run chart of considerably shorter length to assess the efficiency of the above statistical methods, and indicate the process stability.

\section{Methodology}

The methodology involves the following steps:

1. Understanding the basic concepts and tools to detect process stability of a manufacturing process.

2. Process data collection.

3. Approaches used for assessing the statistical stability of the process are

a. Regression Analysis,

b. SR method,

c. INSR method,

d. Run test

e. ANOVA method

f. Levene's test

4. Construction of Run chart using statistical software MINITAB

5. Compare the performance of the above approaches with Run chart.

6. Conclusion about the performance of the above methods. 


\section{WOOLURU ET AL.}

\section{Data collection and analysis}

The data set pertaining to the critical quality characteristic i.e. inner diameter of piston rings for an automotive engine produced by forging process. The details of the operation and product specification are presented in Table 1. The required quality characteristic of 32 consecutive units are measured and presented in Table 2. The basic sample statistics are calculated and presented in Table 3.

Table 1. Product description

\begin{tabular}{rrrrr} 
Part Name & Material & Operation & Specifications & Measuring Device \\
\hline Piston ring & Cast steel & Forging & $74.00 \pm 0.05$ & Dial Gauge \\
\hline
\end{tabular}

*All dimensions are in $\mathrm{mm}$.

Table 2. Measurements of Piston ring hole diameter in $\mathrm{mm}$.

\begin{tabular}{rrrrrrrr} 
SI. no. & Hole dia & SI. no. & Hole dia & SI. no. & Hole dia & SI. no. & Hole dia \\
\hline 1 & 74.030 & 9 & 74.011 & 17 & 73.996 & 25 & 74.014 \\
2 & 74.002 & 10 & 74.004 & 18 & 73.993 & 26 & 74.009 \\
3 & 74.019 & 11 & 73.988 & 19 & 74.015 & 27 & 73.994 \\
4 & 73.992 & 12 & 74.024 & 20 & 74.009 & 28 & 73.997 \\
5 & 74.008 & 13 & 74.021 & 21 & 73.992 & 29 & 73.985 \\
6 & 73.995 & 14 & 74.005 & 22 & 74.007 & 30 & 73.993 \\
7 & 73.992 & 15 & 74.002 & 23 & 74.015 & 31 & 73.998 \\
8 & 74.001 & 16 & 74.002 & 24 & 73.989 & 32 & 73.990 \\
\hline
\end{tabular}

Table 3. Summary Statistics of the case study data.

\begin{tabular}{rrrrrrr} 
Sample size & Mean & Median & Minimum & Maximum & Range & Std. Deviation \\
\hline 32 & 74.003 & 74.002 & 73.985 & 74.03 & 0.045 & 0.0115
\end{tabular}

\section{Statistical Approaches to Detect Instability}

\section{Regression analysis}

One way to quantify the change in location is to fit a straight line to the data using an index variable as the independent in the regression. In this case, the observed 


\section{APPROACHES FOR DETECTION OF UNSTABLE PROCESSES}

values are in the sequential run order and they are collected at equally spaced time intervals. In this study, index variable are $X=1,2,3, \ldots N$ where $N$ is the number of observations. If there is no significant drift in the location over time, the slope parameter would be zero. The scatter diagram of the data reveals a negative linear association. Therefore, it can be proceeded to find the equation of the regression line using MINITAB statistical software.

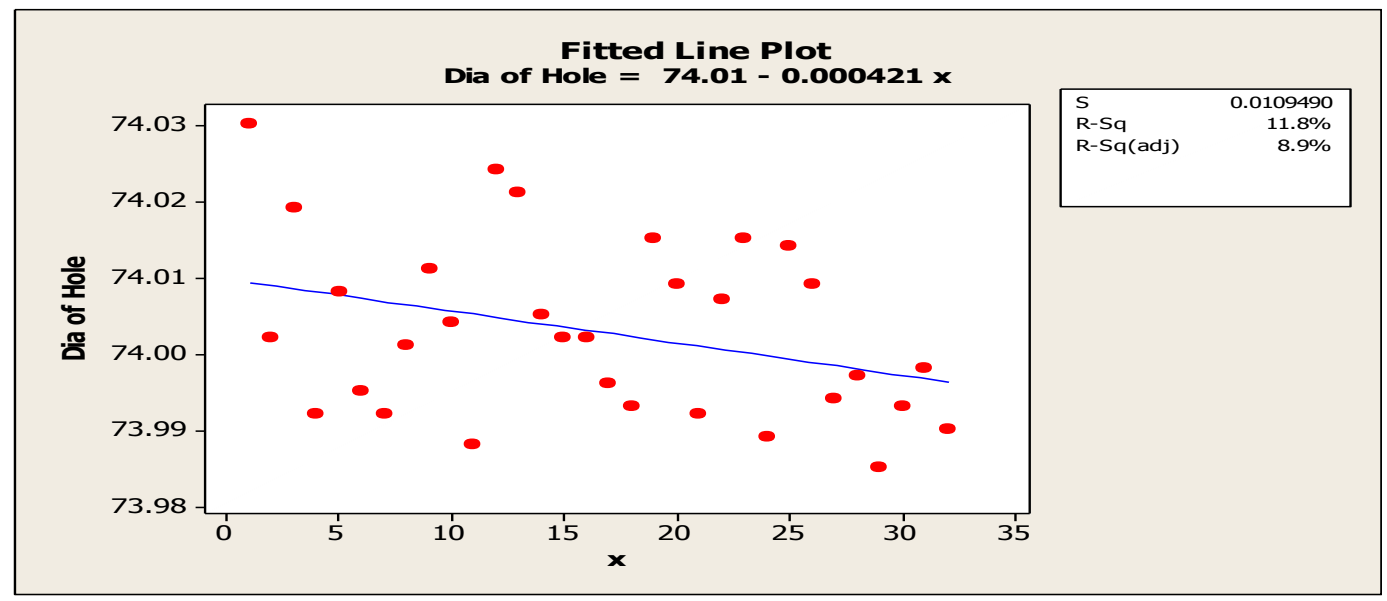

Figure 1. Output of regression analysis table for case study data.

The regression equation is Dia. of Hole $=74.0-0.000421 \times(X)$

\begin{tabular}{rrrrrr}
$\begin{array}{c}\text { Analysis of Variance } \\
\text { Source }\end{array}$ & DF & SS & MS & F & P \\
\hline Regression & 1 & 0.0004831 & 0.0004831 & 4.03 & 0.054 \\
Residual Error & 30 & 0.0035964 & 0.0001199 & & \\
Total & 31 & 0.0040795 & & & \\
\hline
\end{tabular}

In the output of the regression analysis table for the case study data, the $F$-statistic is 4.03 . The table value is 4.17 for $F(0.05,1,30)$. Since $F_{\text {calculated }}$ is less than $F_{\text {table }}$ value, and the $p$-value is greater than 0.05 . It may be concluded that there is evidence that slope is almost equal to zero and ensure the process is stable over time. 


\section{WOOLURU ET AL.}

\section{SR method (standard deviation ratio method)}

The SR test is derived from the square of the ratio of the standard deviation estimated using all the observations and the standard deviation estimated using sub group ranges/standard deviations/individual moving ranges. The basis of the SR test is that if the process is stable, all the approaches would yield similar estimates for the process standard deviation. In this case statistic, SR is computed as the ratio of the estimate of the long term variance and the estimate of the short term variance. The estimated sample variance based on the $N$ observations will indicate the long term variance and the estimated variance based on the moving range $(\mathrm{MR})$ method will reveal the short term variance.

Thus,

$$
\begin{gathered}
S R=\frac{\frac{1}{N-1} \sum_{i=1}^{N}(y-\bar{y})^{2}}{(\overline{M R} / 1.128)} \\
\bar{y}=\sum_{i=1}^{N} Y_{i} / N \\
\overline{M R}=\sum_{i=1}^{N-1}\left|y_{i+1}-y_{i}\right| /(N-1)
\end{gathered}
$$

Ramirez and Runger (2006) assumed that an approximate $F$-distribution for $\mathrm{SR}$, where the effective degree of freedom associated with the numerator and denominator are considered as $(N-1)$ and $0.62 \times(N-1)$ respectively and accordingly, it is recommended as an approximate $F$-test for SR. 


\section{APPROACHES FOR DETECTION OF UNST ABLE PROCESSES}

Table 4. Calculation of Moving Range for the case study data.

\begin{tabular}{rrrrrr} 
SI. no. & Hole dia $\left(y_{i}\right)$ & $M R\left|\left(y_{i+1}-y_{i}\right)\right|$ & SI. no. & Hole dia $\left(y_{i}\right)$ & $M R\left|\left(y_{i+1}-y_{i}\right)\right|$ \\
\hline 1 & 74.030 & - & 17 & 73.996 & 0.006 \\
2 & 74.002 & 0.028 & 18 & 73.993 & 0.003 \\
3 & 74.019 & 0.017 & 19 & 74.015 & 0.022 \\
4 & 73.992 & 0.027 & 20 & 74.009 & 0.006 \\
5 & 74.008 & 0.016 & 21 & 73.992 & 0.017 \\
6 & 73.995 & 0.013 & 22 & 74.007 & 0.015 \\
7 & 73.992 & 0.003 & 23 & 74.015 & 0.008 \\
8 & 74.001 & 0.009 & 24 & 73.989 & 0.016 \\
9 & 74.011 & 0.010 & 25 & 74.014 & 0.025 \\
10 & 74.004 & 0.007 & 26 & 74.009 & 0.005 \\
11 & 73.988 & 0.016 & 27 & 73.994 & 0.015 \\
12 & 74.024 & 0.036 & 28 & 73.997 & 0.003 \\
13 & 74.021 & 0.003 & 29 & 73.985 & 0.007 \\
14 & 74.005 & 0.016 & 30 & 73.993 & 0.008 \\
15 & 74.002 & 0.003 & 31 & 73.998 & 0.005 \\
16 & 74.002 & 0.000 & 32 & 73.990 & 0.008 \\
\hline
\end{tabular}

$$
\begin{aligned}
\bar{y} & =\frac{2368.09}{32}=74.0029, \\
\overline{M R} & =\frac{0.373}{31}=0.0120, \\
\sigma^{\prime} & =\frac{\overline{M R}}{d_{2}}
\end{aligned}
$$

$d_{2}=1.128$, Statistical constant for $n=2$ (Montgomery, 2009, p.702)

$$
\begin{gathered}
\sigma^{\prime}=\frac{0.012}{1.128}=0.0106 . \\
\sum\left|\left(y_{i+1}-y_{i}\right)\right|=0.373 \\
F(0.05,31,19.22)=1.93 F(\text { tab })
\end{gathered}
$$




\section{WOOLURU ET AL.}

Because $S R=0.012$, i.e., $(F$ calculated $), F($ calculated $)<F($ table $)$. Hence, it is concluded that the process is said to be stable.

\section{Instability ratio test (INSR)}

The instability ratio is defined as the ratio of the number of data points that have one or more violation of the Western Electric (1956) rules to the total number of data points plotted in the process behavior chart for the time period under assessment. The motivation for the INSR test is that if the process is stable, then it operates with common cause variation only and over time the observations move randomly about the central line and typically remain within the upper and lower control limits. The pattern exhibited in the run chart is called a random pattern.

Appearance of a nonrandom pattern, which can be detected by applying run rules, is indicative that there is either an assignable cause present in the process or the process output's variation has increased. Ramirez and Runger (2006) considered that the four most popular Western Electric (1956) rules for application of INSR method. Rules are as follows:

- 1 point out side of $3 \sigma$ limits,

- 8 points in a row on one side of the central line,

- 2 of 3 points $2 \sigma$ and beyond on the same side of the central line,

- 4 of 5 points $1 \sigma$ and beyond on the same side of the central line.

Then the test statistic, INSR, is noted as follows

$$
I N S R=\frac{\text { Total number of violations with respect to the four rules in the chart }}{\text { Total number of observations plotted in the chart }} \times 100
$$




\section{APPROACHES FOR DETECTION OF UNSTABLE PROCESSES}

Table 5. Calculation of Moving Range for the case study data.

\begin{tabular}{rrrrrr} 
SI. no. & $\left(y_{i}\right)$ & $M R\left|\left(y_{i+1}-y_{i}\right)\right|$ & SI. no. & $\left(y_{i}\right)$ & $M R\left|\left(y_{i+1}-y_{i}\right)\right|$ \\
\hline 1 & 74.030 & - & 17 & 0.006 & 0.006 \\
2 & 74.002 & 0.028 & 18 & 0.003 & 0.003 \\
3 & 74.019 & 0.017 & 19 & 0.022 & 0.022 \\
4 & 73.992 & 0.027 & 20 & 0.006 & 0.006 \\
5 & 74.008 & 0.016 & 21 & 0.017 & 0.017 \\
6 & 73.995 & 0.013 & 22 & 0.015 & 0.015 \\
7 & 73.992 & 0.003 & 23 & 0.008 & 0.008 \\
8 & 74.001 & 0.009 & 24 & 0.016 & 0.016 \\
9 & 74.011 & 0.010 & 25 & 0.025 & 0.025 \\
10 & 74.004 & 0.007 & 26 & 0.005 & 0.005 \\
11 & 73.988 & 0.016 & 27 & 0.015 & 0.015 \\
12 & 74.024 & 0.036 & 28 & 0.003 & 0.003 \\
13 & 74.021 & 0.003 & 29 & 0.007 & 0.007 \\
14 & 74.005 & 0.016 & 30 & 0.008 & 0.008 \\
15 & 74.002 & 0.003 & 31 & 0.005 & 0.005 \\
16 & 74.002 & 0.000 & 32 & 0.008 & 0.008 \\
\hline
\end{tabular}

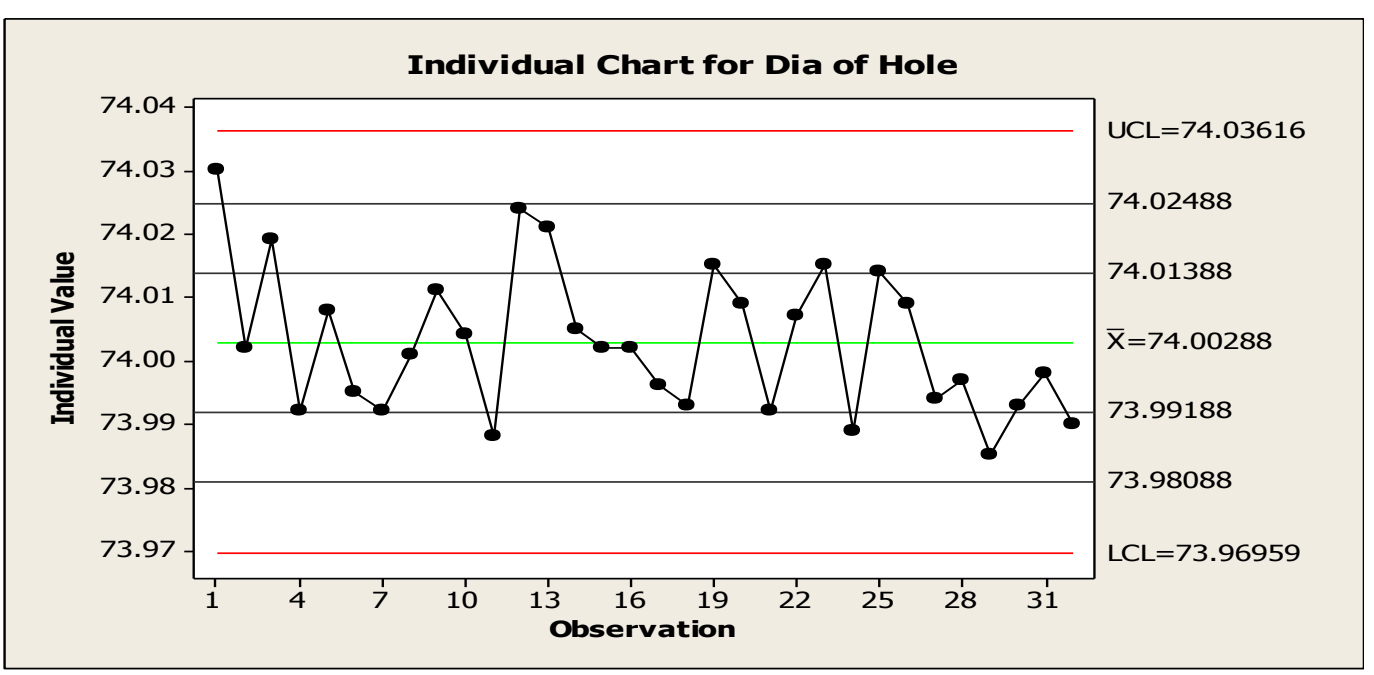

Figure 2. Run chart with $1 \sigma, 2 \sigma$ and $3 \sigma$ control limits. 


\section{WOOLURU ET AL.}

Process mean $(\mu)$ that represents the central line and the standard deviation $(\sigma)$ that determines the distances of the control limits from the central line are usually unknown, and so these may be estimated from the $N$ observations. The process means $(\mu)$ and standard deviation $(\sigma)$ are estimated using arithmetic mean and moving ranges respectively.

\section{Interpretation}

a) 1 point out side of $3 \sigma$ limits, (in Figure 2 no points violate this rule).

b) 8 points in a row on one side of the central line, (in Figure 2 no points violate this rule).

c) 2 of 3 points $2 \sigma$ and beyond on the same side of the central line, (in Figure 2 no points violate this rule).

d) 4 of 5 points $1 \sigma$ and beyond on the same side of the central line, (in Figure 2 no points violate this rule).

e) As no points violating the above 4 rules, INSR $=0.00$, cutoff value for Run chart length $(N=32)$ is $3.125 \%$ [8], so the process is said to be stable.

\section{Variation}

To detect a change in variation in the process, Levene's test has been used it is based on the median rather than the mean. It assesses the assumptions that variance of the population from which different samples are drawn are equal. It tests the null hypothesis that the population variances are equal. If the resulting $p$-value of Levene's test is less than critical value (0.05), the obtained differences in the sample variances are unlikely to have occurred based on random sampling from a population with equal variances thus the null hypothesis of equal variances is rejected and it is concluded that there is a difference between the variances in the population. It also tests whether two sub samples in a given population have equal or different variances based on $p$-values.

Hypothesis Testing: Null hypothesis $H_{0} ; \sigma_{1}=\sigma_{2}=\sigma_{3}=\sigma_{4}$ (There is no change in variance)

Alternate hypothesis, $H_{0} ; \sigma_{1} \neq \sigma_{2} \neq \sigma_{3} \neq \sigma_{4}$ (There is change in variance)

Levine's Test has been carried out using the MINITAB software. Since the $p$-value is greater than 0.05 , the null hypothesis is accepted and hence that there is no change in variance among the 4 sets in the sample data of 32 consecutive units. 


\section{APPROACHES FOR DETECTION OF UNSTABLE PROCESSES}

\section{ANOVA}

This approach is to compare within subgroup variation to between subgroup variation to detect a difference in subgroup means and aimed at detecting changes in the process mean only. In this case study, $N=32$ individual observations are collected and the ANOVA method is applied by forming subgroups of size 2 using consecutive observations, i.e. there will be $N / 2$ subgroups. Then the test statistic $F$ is computed as the ratio of the mean sum of squares of subgroups (MS subgroup) and the mean sum of squares of errors (MS error).

Table 6. Analysis of Variance

\begin{tabular}{rrrrrrrr} 
SI. no. & $x_{1}$ & $x_{2}$ & $\bar{x}_{i}$ & $\bar{x}$ & $\left(\bar{x}_{i}-\bar{x}\right)^{2}$ & $\left(x_{j i}-\bar{x}_{i}\right)^{2}$ & $\left(x_{j i}-\bar{x}\right)^{2}$ \\
\hline 1 & 74.030 & 74.002 & 74.016 & 73.996 & 0.0004 & 0.000392 & 0.001192 \\
2 & 74.019 & 73.992 & 74.0055 & 73.996 & $9.03 \mathrm{E}-05$ & 0.000365 & 0.000545 \\
3 & 74.008 & 73.995 & 74.0015 & 73.996 & $3.02 \mathrm{E}-05$ & $8.45 \mathrm{E}-05$ & 0.000145 \\
4 & 73.992 & 74.001 & 73.9965 & 73.996 & $3.00 \mathrm{E}-07$ & $4.05 \mathrm{E}-05$ & 0.000041 \\
5 & 74.011 & 74.004 & 74.0075 & 73.996 & 0.000132 & $2.45 \mathrm{E}-05$ & 0.000289 \\
6 & 73.988 & 74.024 & 74.006 & 73.996 & 0.0001 & 0.000648 & 0.000848 \\
7 & 74.021 & 74.005 & 74.013 & 73.996 & 0.000289 & 0.000128 & 0.000706 \\
8 & 74.002 & 74.002 & 74.002 & 73.996 & 0.000036 & 0.000000 & 0.000072 \\
9 & 73.996 & 73.993 & 73.9945 & 73.996 & $2.30 \mathrm{E}-06$ & $4.50 \mathrm{E}-06$ & 0.000009 \\
10 & 74.015 & 74.009 & 74.012 & 73.996 & 0.000256 & 0.000018 & 0.00053 \\
11 & 73.992 & 74.007 & 73.9995 & 73.996 & $1.23 \mathrm{E}-05$ & 0.000113 & 0.000137 \\
12 & 74.015 & 73.989 & 74.002 & 73.996 & 0.000036 & 0.000338 & 0.00041 \\
13 & 74.014 & 74.009 & 74.0115 & 73.996 & 0.00024 & $1.25 \mathrm{E}-05$ & 0.000493 \\
14 & 73.994 & 73.997 & 73.9955 & 73.996 & $3.00 \mathrm{E}-07$ & $4.50 \mathrm{E}-06$ & 0.000005 \\
15 & 73.985 & 73.993 & 73.989 & 73.996 & 0.000049 & 0.000032 & 0.00013 \\
16 & 73.901 & 73.87 & 73.8855 & 73.996 & 0.01221 & 0.000481 & 0.024901 \\
\hline
\end{tabular}

Table 7. Resulted values from the ANOVA Analysis.

$\begin{array}{rr}S S_{\text {Factor }}=0.0277684 & M S_{\text {Factor }}=0.001 \\ S S_{E}=0.0026845 & M S_{E}=0.002 \\ S S_{T}=0.03045 & F_{o}=0.98\end{array}$




\section{WOOLURU ET AL.}

From $F_{\text {table }}, F_{\text {critical }}=2.39$ and $F_{\text {calculated }}=0.98$. Since $F_{\text {cal. }}<F_{0.05,15,16 \text {, the }}$ process position in time relating to a hole diameter data is not subjected to significant changes.

\section{Run test for randomness in the sequence.}

It tests the runs up and down or the runs above and below the mean by comparing the actual values to expect values. The statistic for comparison is the chi-square test [6]. All observations in the sample larger than the median value are given a positive sign and those below the median are given negative sign. A succession of values with the same sign is called a run and the number of runs ' $a$ ' in the sequence of data points is found and it from the test statistic. For $n>30$, this test statistic can be compared with a normal distribution with mean and the variance, the test is two-tailed. Data: Sample size: 32 observations, Median: 74.002

Table 8. Values above and below the median.

\begin{tabular}{cccccccc}
\hline 74.030 & 74.002 & 74.019 & 73.992 & 74.008 & 73.995 & 73.992 & 74.001 \\
- & + & - & + & - & - & + & + \\
74.011 & 74.004 & 73.988 & 74.024 & 74.021 & 74.005 & 74.002 & 74.002 \\
- & + & + & - & - & - & - & - \\
73.996 & 73.993 & 74.015 & 74.009 & 73.992 & 74.007 & 74.015 & 73.989 \\
- & + & - & - & + & + & - & + \\
74.014 & 74.009 & 73.994 & 73.997 & 73.985 & 73.993 & 73.998 & 73.990 \\
- & - & + & - & + & + & + & - \\
\hline
\end{tabular}

$H_{0}$ : The sequence is produced in a random manner.

$H_{1}$ : The sequence is not produced in a random manner.

Number of observations, $N=32$, Number of runs, $a=18$

$$
\begin{gathered}
\mu_{a}=\frac{2 N-1}{3} \\
\sigma_{a}^{2}=\frac{16 N-29}{90}
\end{gathered}
$$




\section{APPROACHES FOR DETECTION OF UNST ABLE PROCESSES}

$$
\begin{aligned}
\mu_{a} & =\frac{2(32)-1}{3}=21 \\
\sigma_{a}^{2} & =\frac{16(32)-29}{90}=5.37
\end{aligned}
$$

For $N>20$, the distribution of ' $a$ ' (number of runs) is reasonably approximated by a normal distribution, $N\left(\mu_{a}, \sigma_{a}^{2}\right)$. This approximation can be used to test the independence of the observations. In this case the standardized normal test statistic is developed by subtracting the mean from the observed number of runs ' $a$ ' and dividing by the standard deviation.

The test statistic is as follows.

$$
\begin{gathered}
Z_{0}=\frac{a-\mu_{a}}{\sigma_{a}} \\
Z_{0}=\frac{18-21}{2.32}=-1.30
\end{gathered}
$$

Test statistic: $Z_{0}=-1.30$, Significance level: $\alpha=0.05$

Critical value: $Z_{1-\alpha / 2}=1.96$, Reject $H_{0}$, if $|Z|>1.96$.

In this case, the test statistic (-1.30) is inside the critical region, the null hypothesis cannot be rejected and hence it is concluded that the data is random. The critical value $Z_{0.025}=1.96$. Because $\left|Z_{0}\right|<Z_{0.025}$, the independence (randomness) of the sequence of the observations cannot be rejected.

\section{Run chart analysis}

A run chart is a line graph of data plotted over time. By collecting and charting data over time, trends or patterns in the process can be revealed. As run charts do not use control limits, they cannot exhibit if a process is stable. However, they can show that how the process is running. The run chart can be a valuable tool at the beginning of a manufacturing process, as it reveals important information about a process before collecting the enough data to create reliable control limits. Figure 3 shows the Run chart for the case study data constructed using statistical software MINITAB to assess the stability of the process. 


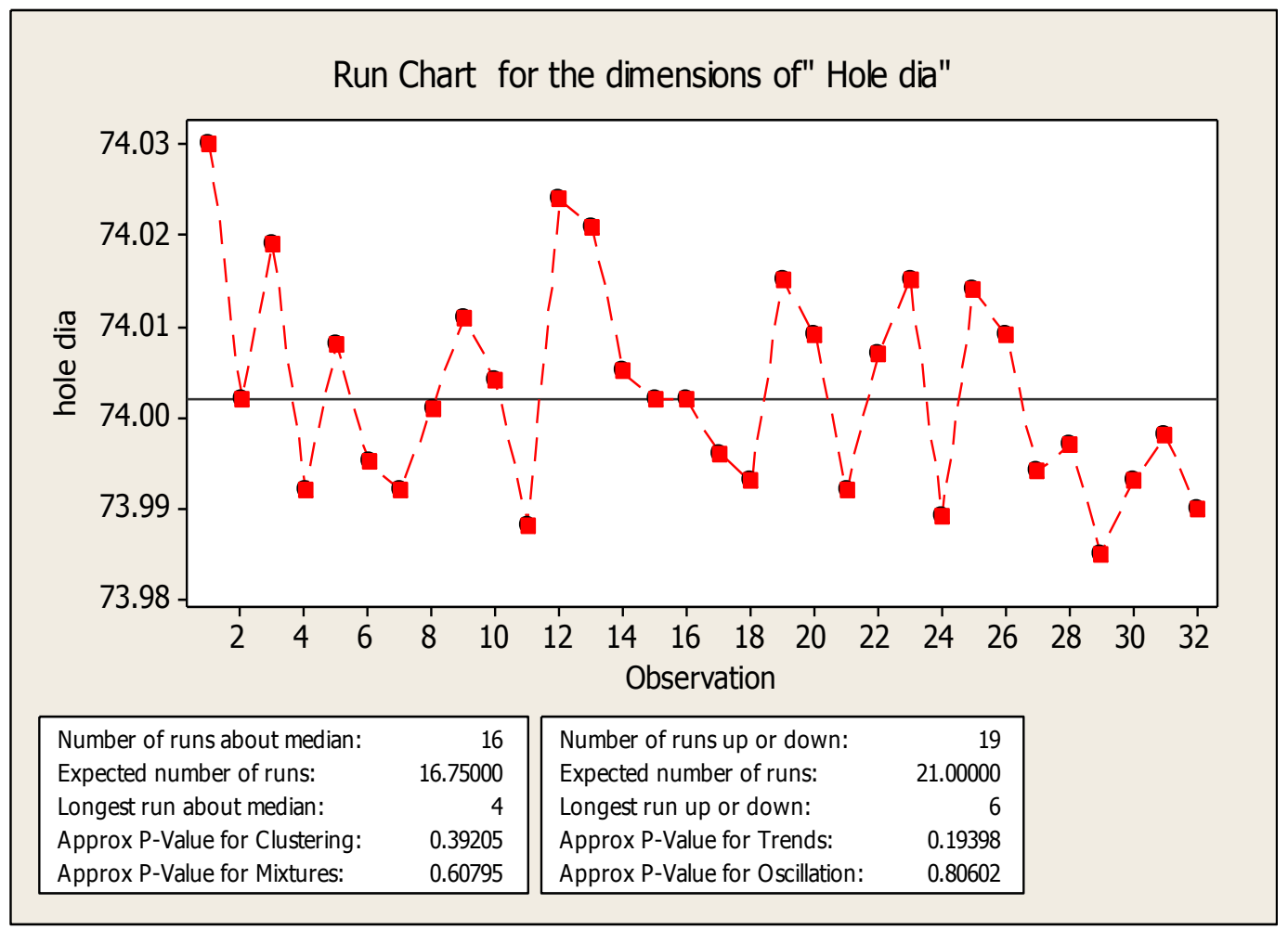

Figure 3. Construction of run chart using MINITAB-Statistical software.

The two tests (actual number of runs about median and number of runs up and down) have been conducted to check the randomness. In both the tests i.e., actual number of runs about median and number of runs up and down are close to the expected number of runs. It implies that the data come from random distribution. Clusters are groups of points in one area of the charts, cluster indicate variation due to special causes such as measurement problem. In this case, approximate $p$-value is 0.39205 , it is greater than 0.05 , hence it may be concluded that there is no clustering in the data. Process stability can be assured by observing the oscillation of data above and below the center line rapidly. In this case, Approximate $p$-value is 0.80602 , it is greater than 0.05 , so it may be conclude that there is no oscillating pattern in the data.

A mixture is characterized by an absence of points near the center line. It often indicates combined data from two populations or two processes operating at different levels. In this case, approximate $p$-value is 0.60795 , it is greater than 0.05 , hence it may be conclude that the data does not come from different process. 


\section{APPROACHES FOR DETECTION OF UNST ABLE PROCESSES}

Trends are sustained and systematic sources of variation characterized by a group of points that drifts either up or down. Trends may warn that a process is about to go out of control and may be due to worn tools. In this case, approximate $p$-values is 0.19398 , it is greater than 0.05 , hence it is concluded that there is no trend in the data. The tests for non-random pattern are significant at the 0.05 level. All $p$-values for all the tests are greater than $0.05(\alpha)$ which suggests that the data come from a random distribution and process is stable.

\section{Discussion}

The data set pertaining to the quality characteristic i.e. inner diameter of piston rings for an automotive engine produced by forging process. Measurements for inner diameter of 32 consecutive units are measured and recorded. The various approaches have been used on the data in order to assess the stability of the forging process. Tests with respect to location, variation, randomness and sequence of data has been done through Regression analysis, ANOVA test, Run test, Levene's test, SR test, INSR test. The scatter plot reveals a least magnitude of negative linear association (almost zero).

In Regression analysis, $R^{2}$ value is $11.8 \%$; it is can be stated that $11.8 \%$ of the total variation in the hole diameter occurs because of the variation in the observations sequence and remaining $88.2 \%$ is due to randomness and other causes of variation and also reveals that the relationship between the variables i.e. hole diameter and time is not significant. Also the F-test indicates that there is no considerable slope in the line.

In Levene's test, P-valve is greater than 0.05 , so the null hypothesis cannot be rejected that there is no change in variance among the 4 sets in the sample data of 32 consecutive units.

In case of Instability ratio test, Calculated Instability Ratio (INSR) $=0.00$, cutoff value for Run chart length $(N=32)$ is $3.125 \%$ [8], as instability ratio value is less than cutoff value, the process is said to be stable. In SR method, the test statistic SR is computed and compared with the $F$ (table) value. F-Test for SR, conclude that the process is stable as $\mathrm{SR}=0.012$ i.e. ( $F$ calculated) is less than $F(0.05,31,19.22)=1.93$ i.e., $(F$ table $)$. In case of ANOVA method, $N=32$ individual observations, it is applied by forming subgroups of size 2 using consecutive observations, i.e. there will be N/2 subgroups.

Then the test statistic $F$ is computed as the ratio of the mean sum of squares of subgroups (MS subgroup) and the mean sum of squares of errors (MS error).

From $F_{\text {table }}, F_{\text {critical }}=2.39$ and $F_{\text {calculated }}=0.98$. Since $F_{\text {calculated }}<F_{0.05,15,16}$, the 


\section{WOOLURU ET AL.}

process position in time relating to a hole diameter is not subjected to significant changes. Run Test for randomness of the sequence is concluded that the data is random. The Table 9 presents the summary of results of the various statistical methods.

Table 9. Summary results of the statistical method.

\begin{tabular}{rrrr} 
SI. no. & Statistical method & Result & Stable/Unstable \\
\hline 1 & Regression & $F($ calculated $)<F($ table $), p>0.05$ & Stable \\
2 & SR-method & $F($ calculated $)<F($ table $)$ & Stable \\
3 & Instability Ratio method & Instability ratio $<$ cutoff value, & Stable \\
4 & Levene's Test & $p>0.05$ & Stable \\
5 & ANOVA method & $F($ calculated $)<F($ table $)$, & Stable \\
6 & Run Test & $Z$ Zo (calculated $)<Z$ - 2 (table), & Stable \\
7 & Run Chart & $p>0.05$, All cases & Stable \\
\hline
\end{tabular}

Alternative approaches were presented to assess the stability of the process and compared with the run chart. Process stability has been detected using the approaches such as Regression analysis, SR method, INSR method, Levene's test, ANOVA method. Even though all the approaches yield the same result (i.e., process is stable), above mentioned approaches have their own advantages and limitations. As the exact distribution of SR is not known and assumed an approximate F-distribution for SR, it can be applied only when the number of observations is larger than or equal to 32. The advantage of ANOVA approach is that the F-test conducted using the 'between' and 'within' sums of squares is well defined and it is applicable even when the available number of observations is small but it requires practitioner's to have background in statistics. Run test indicated that the data points are independent and random, hence it is concluded that there is no shift in location. INSR Test is more effective test as it uses rules similar to run chart and it works well for large number of samples. For small number of samples like 32-100 subgroups it leads to a Type-I error (i.e. probability of declaring a stable process as unstable) as high as 0.35 . Ramirez and Runger recommended taking the $95^{\text {th }}$ percentile point of the distribution of INSR as the cutoff value. With aim to increase the effectiveness, it has been recommended using the ANOV and the INSR tests. All the statistical methods indicates the presence of statistical stability in the case study data but run chart using the statistical software MINITAB gives more effective and accurate result compared to the other methods for assessing stability of the process. 


\section{APPROACHES FOR DETECTION OF UNST ABLE PROCESSES}

\section{References}

Banks, J. (1989). Principles of quality control. New York, NY: John Wiley \& Sons.

Banks, J., Carson II, J. S., Nelson, B. L., Nicol, D. M. (2001). Discrete-event simulation ( $3^{\text {rd }}$ ed.). Prentice - Hall of India.

Champ, C. W. \& Woodall, W. H. (1987). Exact results for Shewhart control chart for supplementary runs rules. Technometrics, 29(4), 393-399. doi:10.1080/00401706.1987.10488266

Czarski, A. (2009). Assessment of a long-term and short-term process capability in the approach of analysis of variance (ANOVA), Metallurgy and Foundry Engineering, 35(2), 111-119. doi:10.7494/mafe.2009.35.2.111

Deming, W. E. (1986). Out of the crisis. Cambridge, MA: Massachusetts Institute of Technology, Center for Advanced Engineering Study.

Gouri, S. K. (2010). A quantitative approach for detection of unstable processes using a run chart. Quality Technology and Quantitative Management, 7(3), 231-247.

Grant, E. L. \& Leavenworth, R. S. (1996). Statistical quality control (7th ed.). New York. NY: McGraw-Hill.

Montgomery, D. C. (2001). Introduction to statistical quality control (4th ed.). New York, NY: John Wiley \& Sons.

Montgomery, D. C. (2009). Introduction to statistical quality control (pp. 702) (6th ed.). New York, NY: John Wiley \& Sons.

Nelson, L. S. (1984). The Shewhart control chart -- test for special causes. Journal of Quality Technology, 16(4), 237-239.

Nelson, L. S. (1985). Interpreting Shewhart X-bar control charts. Journal of Quality Technology, 17(2), 114-116.

Pham, D. T. \& Wani, M. A. (1997). Feature based control chart pattern recognition. International Journal of Production Research, 35(7), 1875-1890. doi:10.1080/002075497194967

Prabhuswamy. M. S. \& Nagesh. P. (2007). Process capability analysis made simple through graphical approach. Kathmandu University Journal of Science, Engineering and Technology, l(3).

Prabhuswamy. M. S. \& Nagesh, P. (2010-2011). Process capability validation and short - Long term process capability analysis with case study. Proceedings of ETIMES-2006. 


\section{WOOLURU ET AL.}

Ramirez, B. \& Runger, G. (2006). Quantitative techniques to evaluate process stability. Quality Technology, 18(1), 53-68.

doi:10.1080/08982110500403581

Western Electric (1956). Statistical quality control handbook. Indianapolis, IN: Western Electric Company. 